\title{
MODEL PENGENDALIAN KATODIK DALAM ELEKTRODE DISK PEMUTAR SISTEM KOROSI
}

\author{
ISNI UTAMI \\ Dosen Teknik Industri UPN "Veteran “ Jawa Timur \\ E-mail: isniutami@yahoo.com
}

\begin{abstract}
ABSTRAK
Efek dari aliran fluida memerlukan pengendalian katodik dengan karakteristik menggunakan model rotating disk electrode (RDE) telah diteliti di peraturan elektrokimia. Penelitian ini diselesaikan untuk logam AISI 1018 sebagai pemutar elektrode berbentuk silinder di dalam pembagian udaraNaCl 3.5\% menggunakan variasi rata-rata putaran 0-2000 rpm dan temperatur $25-27^{\circ} \mathrm{C}$. Kepadatan pengendali katodik ditentukan dari logam permukaan potensial $-800 \mathrm{mV}$ dengan anoda $\mathrm{Ag} / \mathrm{AgCl}$. Eksperimen menunjukkan bahwa peningkatan laju elektrode, kepadatan pengendali katodik saat ini membutuhkan peningkatan karena difusi lapisan faksi tara dan juga karena potensial korosi menjadi lebih positif. Temperatur yang lebih tinggi akan meningkatkan pengendali kepadatan katodik dan membuat potensial korosi menjadi negative. Energi aktivasi oksigen akan bergabung ke dalam permukaan electrode untuk membantu corrodibility AISI 1018 bergantung peningkatan temperatur, karena reaksi katodik dikontrol dari perubahan massa oksigen.
\end{abstract}

Kata kunci: model pengendalian katodik, elektronik disk rotating, korosi

\begin{abstract}
The effect of fluids flow rate onto necessity of current density cathodic protection which characterized using Rotating disk electrode (RDE) model has been researched on an electrochemistry manner. This research was done to AISI 1018 steel as the electrode spinning cylinder-shaped inside aerated dissolvable $\mathrm{NaCl} 3.5 \%$. using variation spinning rate 0-2000rpm and $25-75^{\circ} \mathrm{C}$ temperature. Current density cathodic protection necessity determined from the steel interface potential $800 \mathrm{mV}$ with reference anode $\mathrm{Ag} / \mathrm{AgCl}$. Experiment result shows that the increasing of electrode rate, cathodic protection current density needs increased due to diffusion layer tare faction and also because corrosion potential become more positive. Higher temperature would increase cathode protection current density needs and makes corrosion potential more negative. Oxygen activation energy value to be diffused onto electrode surface support the corrodibility AISI 1018 toward temperature increment, because cathodic reaction controlled by transfer mass of dissolved oxygen.
\end{abstract}

Key word: cathodic protection model, rotating disk electrode, corrodibility

\section{PENDAHULUAN}

Model pengendalian korosi pada dasarnya dapat dikelompokkan menjadi dua kelompok, yaitu Model Kinetika dan Model Termodinamika (Bard and Faulkner, 1980). Dalam Model Kinetika, pengendalian korosi dilakukan dengan memberi hambatan pada interaksi dengan lingkungannya sehingga laju korosinya dapat dikurangi, tetapi kecenderungan untuk terjadinya korosi itu sendiri tidak diselesaikan,sehingga apabila hambatan ditiadakan korosi akan segera berlangsung lagi (Jones, 1992). Selain dari pada itu apabila jumlah hambatan yang ditambahkan tidak mencukupi maka korosi akan menjadi lebih parah lagi misalnya terjadinya korosi setempat. Salah satu Model Termodinamika yang diterapkan secara luas adalah Model proteksi katodik (Fontana, 1979).
Prinsip proteksi katodik sebenarnya sederhana, yaitu dengan cara memperlakukan struktur logam yang diproteksi sebagai katoda, dengan jalan mengalirkan arus listrik melalui elektrolit ke logam yang diproteksi (Blount,1989). Atas dasar prinsip inilah cara pengendalian korosi dengan teknik proteksi katodik diterapkan dalam praktek, terutama dalam pengendalian baja yang berada dalam elektrolit misalnya tanah basah atau dalam air laut. Besar kecilnya rapat arus yang harus dialirkan bergantung dari laju korosinya. Makin besar laju korosinya makin besar pula makin besar pula jumlah rapat arus proteksi yang diperlukan untuk memproteksi katodik (Shreir, 1994). Laju korosi baja dipengaruhi oleh banyak faktor diantaranya oleh laju alir fluida. Sebagai contoh kapal yang bergerak laju korosinya lebih besar dari pada kapal yang diam 
(Berendsen, 1987). Dari penelitian F.Laque yang dikutip oleh (H.H. Uhlig, 1985) laju korosi baja dalam lingkungan air laut akan meningkat secara parabolik dengan bertambahnya kecepatan relatif. Pernyataan tersebut diperkuat oleh (John Morgan, 1987) yang menyatakan rapat arus proteksi katodik meningkat secara parabolik dengan bertambahnya kecepatan kapal.

Tujuan penelitian ini untyk mengerahui pengaruh laju alir fluida terhadap keperluan rapat arus proteksi katodik, sehingga kemungkinan kesalahan desain dapat terjadi,dan hal ini dapat mengakibatkan kegagalan.Kajian pengaruh laju alir fluida terhadap keperluan rapat arus proteksi katodik yang dinyatakan dalam persamaan empiris diperlukan untuk mempermudah perhitungan di dalam desain proteksi baja yang mempunyai kecepatan relatif, yang sampai saat ini belum ada. Penelitian pengaruh laju alir fluida terhadap keperluan rapat arus proteksi katodik telah banyak dilakukan, akan tetapi hasil penelitian terdahulu banyak dinyatakan dalam bentuk grafis dan angka, belum dalam bentuk model.

\section{METODE}

Pendekatan masalah mengacu (Geoffery Prentice, 1991) yang menyatakan dalam suatu reaksi korosi logam jika perpindahan massa sebagai langkah penentu laju yang disebabkan perpindahan karena pengadukan atau perpindahan hidrodinamika ,maka besarnya rapat arus korosi merupakan fungsi bilangan tak bermatra sebagai berikut:

$$
\mathrm{i}_{\mathrm{L}} \quad=\frac{\mathrm{nFDC}}{\mathrm{L}} \mathrm{f}(\mathrm{Re}, \mathrm{Sc})
$$

$$
\frac{\mathrm{i}_{\mathrm{L}} \mathrm{L}}{\mathrm{nFDC}}=\mathrm{f}(\mathrm{Re}, \mathrm{Sc})
$$$$
\text { Sh } \quad=f(\operatorname{Re}, S c)
$$

Berturut turut bilangan Sherwood(Sh),bilangan Reynolds(Re),dan bilangan Schmidt (Sh). Dengan analisis bilangan tak bermatra dapat dicari kelompok kelompok bilangan bilangan tak bermatra sebagai berikut:

$$
\mathrm{i}_{\mathrm{PRDE}}=\mathrm{KnFCr}^{-1} v\left[\frac{\mathrm{r}^{2} \omega}{v}\right] \stackrel{{ }_{3}^{\mathrm{c}}}{3}\left[\frac{v}{\mathrm{D}}\right]^{-\mathrm{c}}{ }_{1}
$$

Dengan manipulasi aljabar persamaan akan didapat:

$$
\mathrm{i}_{\mathrm{PRDE}}=\frac{\mathrm{KnFCD}}{\mathrm{r}}[\mathrm{Re}]^{\mathrm{a}_{1}}[\mathrm{Sc}]^{\mathrm{a}_{2}}
$$

Persamaan empiris tersebut, menunjukkan hubungan antara pengaruh laju alir fluida terhadap keperluan rapat arus proteksi katodik. Penelitian berupaya untuk menentukan harga-harga Konstanta $\mathrm{K}, \mathrm{a}_{1}$, dan $\mathrm{a}_{2}$ yang akan ditentukan melalui simulasi percobaan-percobaan di laboratorium.

Pada penelitian ini sebagai peubah tetap adalah baja AISI - SAE 1018, sedangkan peubah bebas yang dikerjakan adalah:

Sebagai lingkungan , larutan $\mathrm{NaCl} 3,5 \%$

Suhu yaitu $25^{\circ} \mathrm{C}, 50^{\circ} \mathrm{C}, 75^{\circ} \mathrm{C}$

Kecepatan RDE pada rentang 0-2000 rpm

Pada penelitian ini digunakan Potensiostat Gamry Instrument yang dilengkapi dengan "Programmable DC Power Supply". Reaksi reduksi dilangsungkan dalam sel elektrolisis yang dilengkapi dengan elektroda kerja berbentuk piringan berputar dari baja. Kecepatan elektroda kerja dikendalikan oleh motor pengaduk, dan sumber arus listrik dihubungkan dengan sikat sikat yang terbuat dari Graphalloy. Elektroda bantu terbuat dari kawat platina berbentuk jaring ditempatkan mengelilingi dinding sel. $\mathrm{Ag} / \mathrm{AgCl}$ ( kalibrasi +0,202 Volt terhadap SHE pada suhu $25^{\circ} \mathrm{C}$ ) digunakan sebagai elektroda referensi, yang dicelupkan pada larutan.Selama proses elektrolisis sistem dalam keadaan tertutup sehingga tidak ada gas yang keluar. Untuk memperoleh data yang akurat, sebelum polarisasi dimulai elektroda kerja diputar di dalam sel elektrolisis sampai diperoleh potensial korosi yang relatif tetap.Pengukuran keperluan rapat arus proteksi katodik dilakukan dengan metoda potensiodinamik. Polarisasi katodik dilakukan dengan laju penambahan potensial sebesar $0,5 \mathrm{mV} /$ det. Penentuan keperluan rapat arus proteksi katodik ditentukan pada potensial baja - $850 \mathrm{mVolt}$ dengan elektroda $\mathrm{Ag} / \mathrm{AgCl}$.

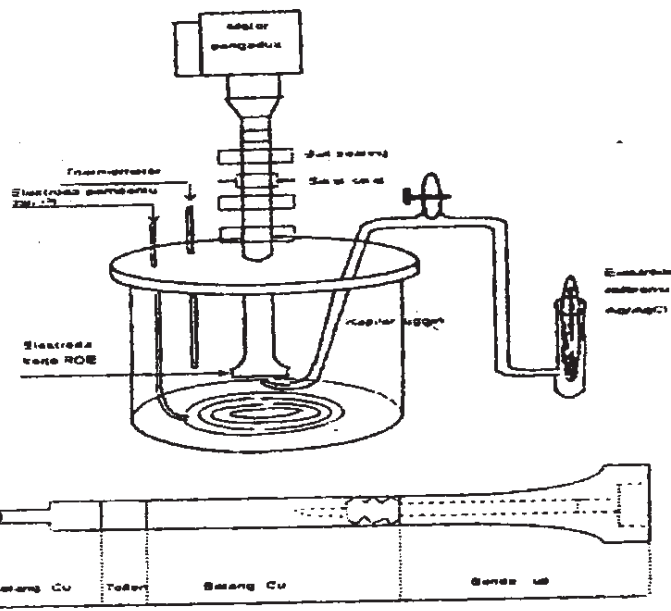

Gambar 1. Skema rangkaian alat potensiostat 


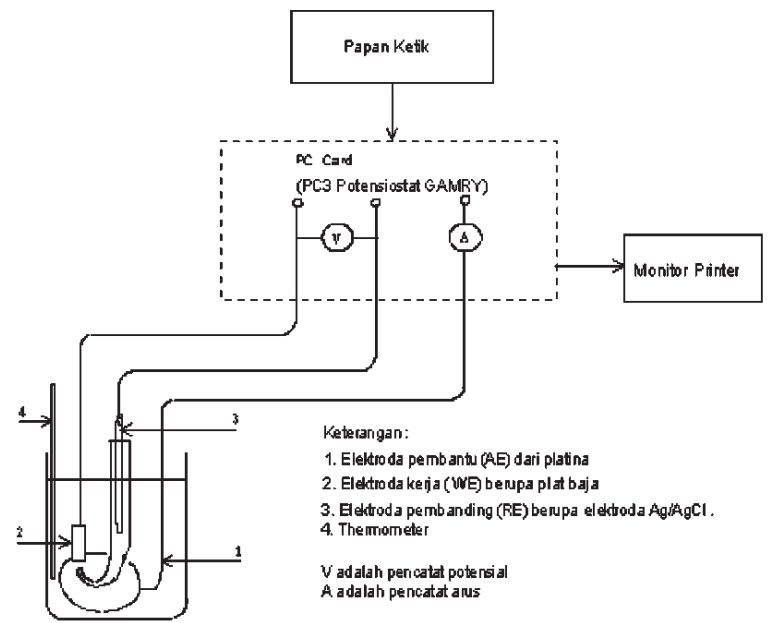

\section{HASIL DAN PEMBAHASAN}

Dari setiap percobaan polarisasi baja AISI-SAE 1018 dalam larutan $\mathrm{NaCl}$ 3,5\% teraerasi dilakukan untuk menentukan besarnya rapat arus proteksi katodik pada suhu $25-75^{\circ} \mathrm{C}$ dengan variasi kecepatan pada rentang 0-2000 rpm, diperoleh kurva polarisasi sebagai berikut:

Dari kurva polarisasi katodik pada (gambar 3). dapat ditentukan dua parameter yaitu potensial korosi dan besarnya keperluan rapat arus proteksi katodik pada kriterium - 800 mVolt dengan elektrode referensi $\mathrm{Ag} / \mathrm{AgCl}$.Dari parameter tersebut dapat ditentukan hubungan pengaruh laju alir fluida terhadap keperluan rapat arus proteksi katodik.

Gambar 2. Skema sel elektrolisis RDE

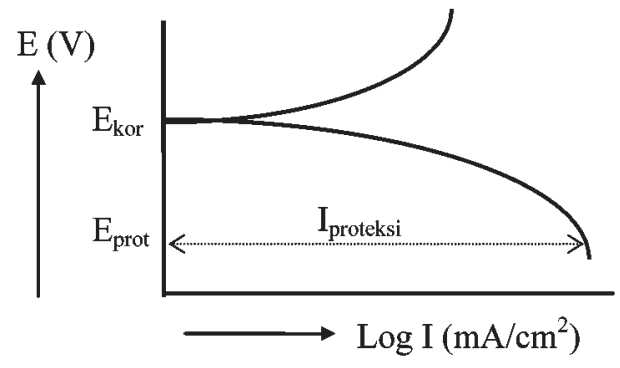

Gambar 3. Skema kurva polarisasi baja dalam larutan $\mathrm{NaCl} 3,5 \%$ pada $\mathrm{pH} 7,2$ dan teraerasi.

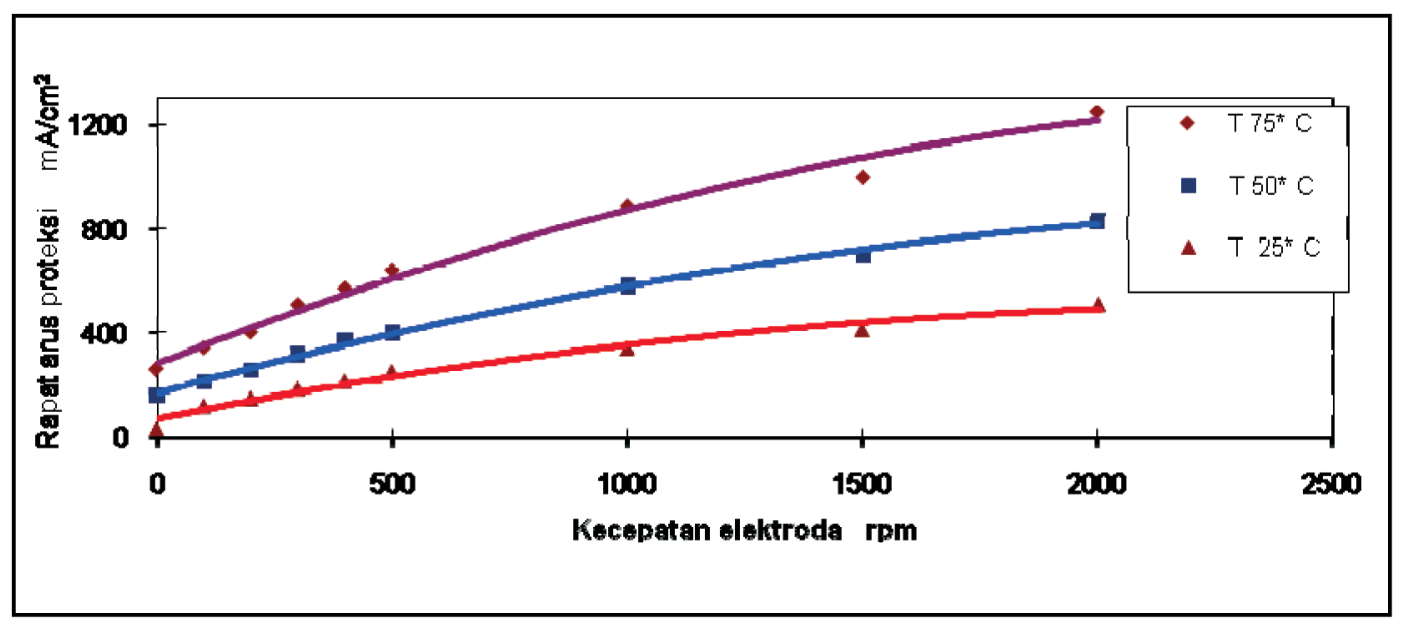

Gambar 4. Pengaruh kecepatan elektroda terhadap keperluan rapat arus proteksi katodik AISI - SAE 1018 (RDE) dalam larutan $\mathrm{NaCl} 3,5 \%$ teraerasi 


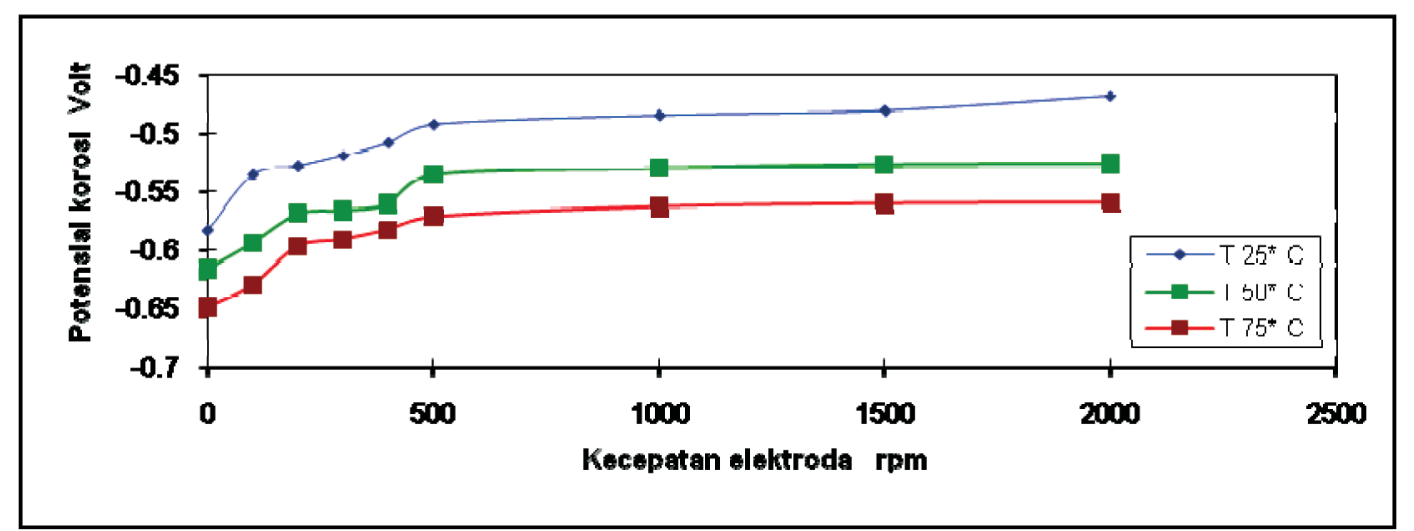

Gambar 5. Pengaruh kecepatan elektroda terhadap potensial korosi AISI - SAE 1018 (RDE) dalam larutan NaCl 3,5\% teraerasi

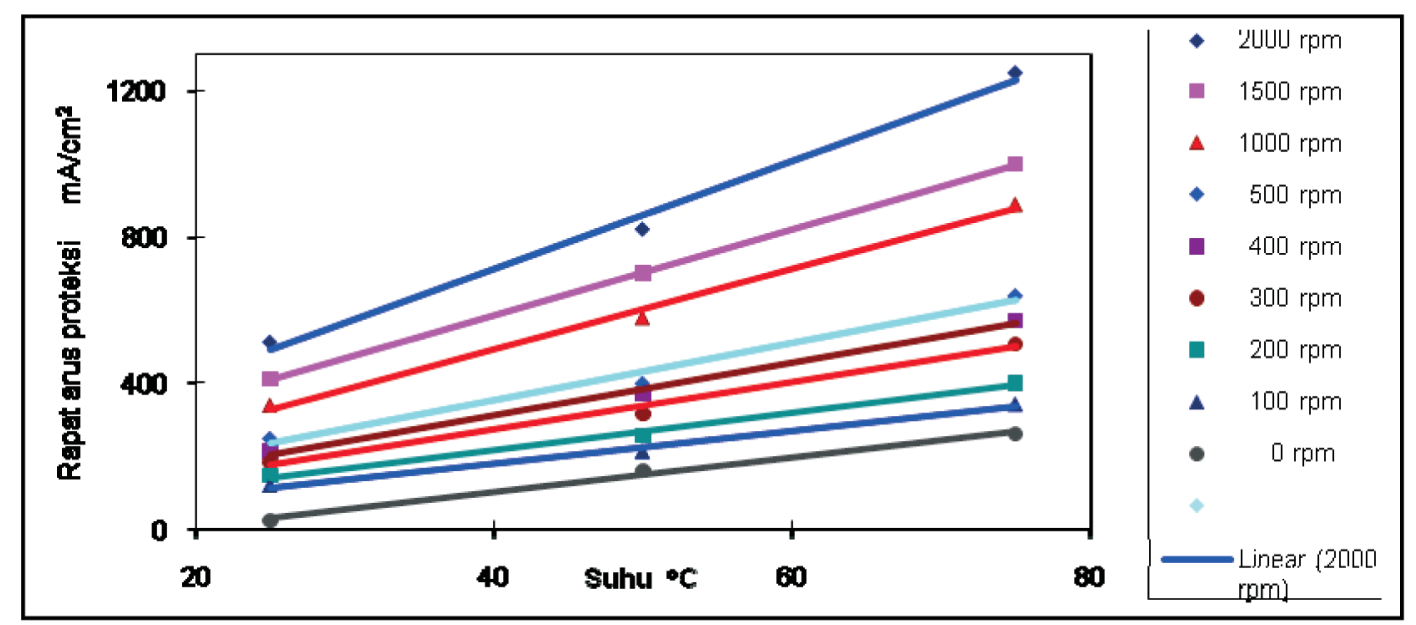

Gambar 6. Pengaruh suhu terhadap keperluan rapat arus proteksi katodik AISI - SAE 1018 (RDE) dalam larutan $\mathrm{NaCl} 3,5 \%$ teraerasi

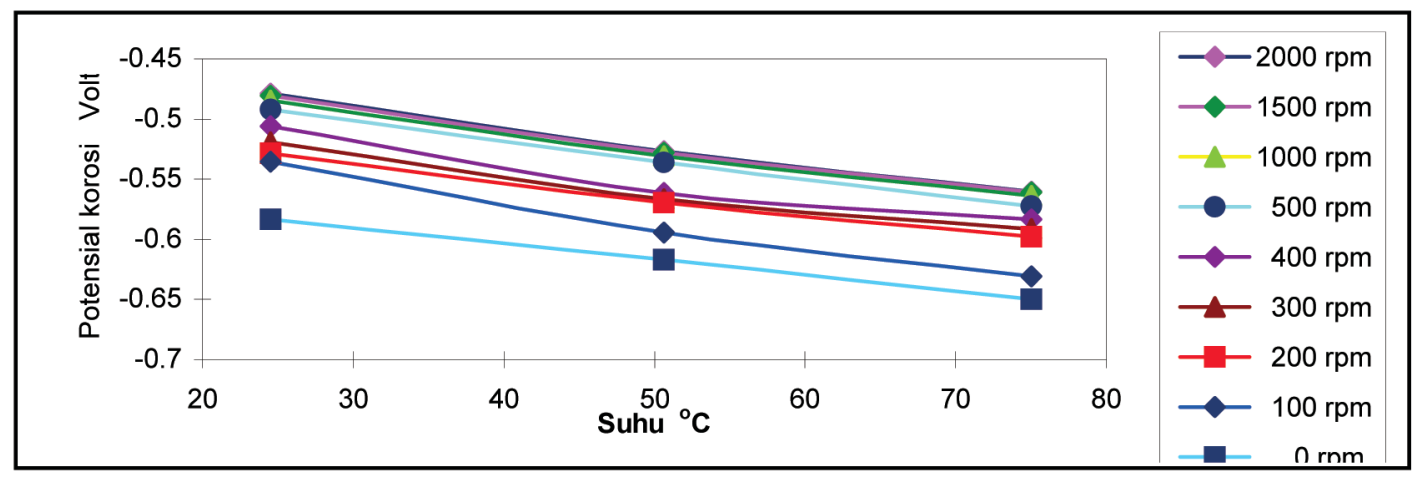

Gambar 7. Pengaruh suhu terhadap potensial korosi AISI - SAE 1018 (RDE) dalam larutan NaCl 3,5\% teraerasi 


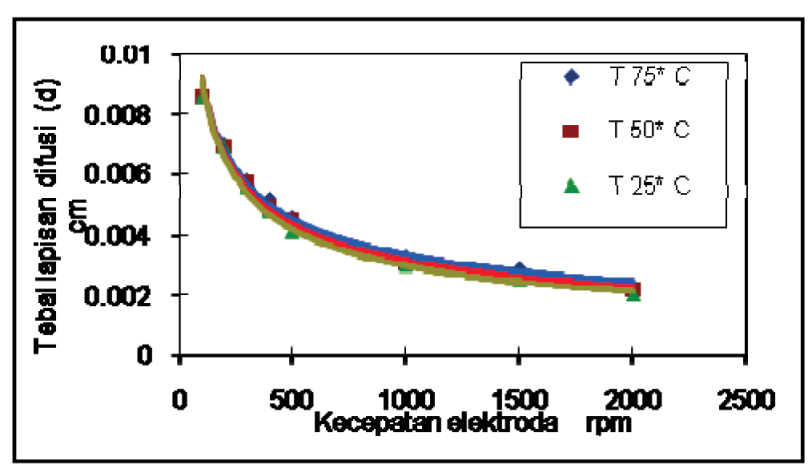

Gambar 8. Hubungan pengaruh kecepatan elektroda (RDE)

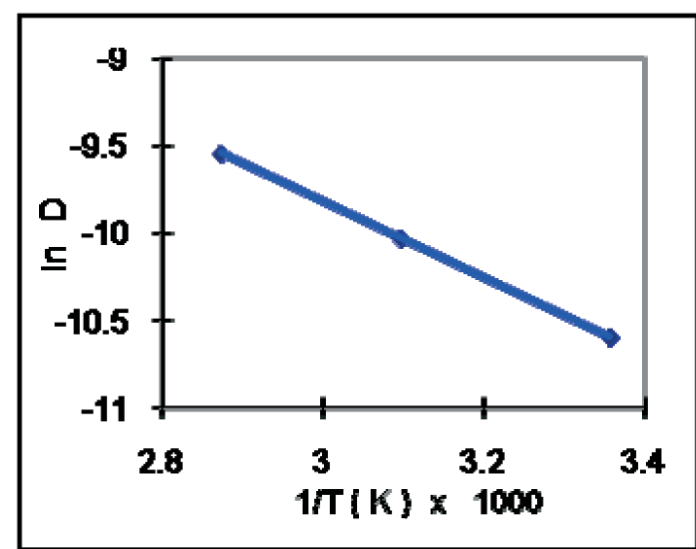

Gambar 9. Kurva ln D terhadap $1 / \mathrm{T}$ terhadap tebal lapisan difusi AISI-SAE 1018 dalam larutan $\mathrm{NaCl} 3,5 \%$ teraerasi

Dari hasil serangkaian percobaan baja AISI 1018 dalam larutan $\mathrm{NaCl} 3,5 \%$ teraerasi pada $\mathrm{pH}$ 7,2 dengan variasi kecepatan pengadukan pada rentang 0-2000 rpm dan suhu $25-75^{\circ} \mathrm{C}$, didapatkan bahwa besarnya keperluan rapat arus proteksi dipengaruhi oleh kecepatan pengadukan dan suhu yang dinyatakan dalam persamaan empiris sebagai fungsi bilangan Schmidt, Rynold dan Sherwood.

Sebagaimana yang dapat dilihat pada gambar 4 meningkatnya kecepatan pengadukan akan meningkatkan laju korosi baja AISI 1018 dan keperluan rapat arus proteksi , hal ini disebabkan dengan adanya pengadukan ion-ion logam di antarmuka logam-larutan elektrolit lebih cepat mencapai ruah, yang ditunjukkan dengan semakin tipisnya tebal lapisan difusi, sehingga laju korosinya juga meningkat. Hubungan pengaruh kecepatan pengadukan pada berbagai suhu terhadap tebal lapisan difusi ditunjukkan pada gambar 8. Selain dari pada itu potensial korosinya meningkat dengan meningkatnya kecepatan pengadukan gambar 5 .
Kenaikan suhu $\left(25-75^{\circ}\right.$ C) juga akan meningkatkan laju korosi baja AISI 1018 dan keperluan rapat arus proteksi katodik gambar 6.Meningkatnya keperluan rapat arus proteksi ini disebabkan difusi oksigen ke permukaan elektroda meningkat dengan kenaikan suhu sehingga laju korosinya juga meningkat, yang dapat dijelaskan dengan penerapan rumus Arrhenius sebagai berikut:

$\mathrm{D}_{\mathrm{i}}=\mathrm{D}_{\mathrm{io}} \exp \left[\frac{Q^{*}}{R T}\right]$

Dari rumusan tersebut dapat disimpulkan bahwa difusi oksigen ke permukaan elektroda meningkat dengan meningkatnya suhu dan potensial korosinya lebih negatif gambar 7, sehingga laju korosinya juga meningkat.Dengan mengalurkan Ln D terhadap 1/T yang berupa garis lurus (gambar 9) dapat ditentukan besarnya energi aktivasi oksigen untuk berdifusi.

Sebagaimana telah diuraikan pada tinjauan pustaka, hubungan fungsional pengaruh kecepatan pengadukan/laju alir fluida dan suhu terhadap keperluan rapat arus proteksi katodik untuk regim aliran turbulendituliskan sebagai berikut:

$\mathrm{i}_{\text {PRDE }}=\mathrm{K} \frac{n F C D}{r}[R e]^{\mathrm{a}_{1}}[\mathrm{Sc}]^{\mathrm{a}_{2}}$

Dari data-data hasil percobaan yang diperoleh, dapat dihitung nilai koefisien $\mathrm{K}, \mathrm{a}_{1}$ dan $\mathrm{a}_{2}$. Dengan menggunakan analisis regresi linier ganda diperoleh nilai $\mathrm{K}, \mathrm{a}_{1}$, dan $\mathrm{a}_{2}$, sehingga rumusan keperluan rapat arus proteksi katodik untuk metode RDE yang dianggap sebagai regim aliran turbulen adalah sebagai berikut:

$$
\mathrm{i}_{\mathrm{PRCE}}=2,219 \frac{n F C D}{r}[R e]^{0,4664}[\mathrm{Sc}]^{0,251}
$$

\section{Notasi}

$\mathrm{i}_{\text {PRDE }}$ rapat arus proteksi katodik $\quad \mathrm{mA} / \mathrm{cm}^{2}$

D koefisien difusi spesi i $\quad \mathrm{cm}^{2} / \mathrm{det}$

$\mathrm{r}$ jari jari elektroda kerja $\mathrm{cm}$

$\omega \quad$ kecepatan putar elektroda kerja det $^{-1}$

$v$ viskositas kinematik $\quad \mathrm{cm}^{2} / \mathrm{det}$

$\mathrm{n} \quad$ jumlah elektron yang

dipertukarkan

C konsentrasi spesi i mol/lt

F konstanta Faraday C/ekuivalen

\section{SIMPULAN}

Dari hasil penelitian dapat disimpulkan bahwa persamaan empiris yang merupakan hubungan 
fungsional anatara pengaruh kecepatan elektroda/ laju alir fluida yang dikarakterisasi sebagai aliran laminer terhadap keperluan rapat arus proteksi katodik adalah sebagai berikut:

$\mathrm{i}_{\mathrm{PRCE}}=2,219 \frac{n F C D}{r}[R e]^{0,4664}[\mathrm{Sc}]^{0,251}$

\section{DAFTAR PUSTAKA}

Berendsen A.M. 1987. Ship Painting Manual. Delf, Bard A.J. and Faulkner L.R. 1980. Electrochemical Methods, Fundamental and Application. John Willey \& Sons, New York.

Blount F.E. 1989. Electrochemical Prinsiples of Cathodic Protection Corrosion Control. NACE vol 10, No 7.

Chawla S.L and Gupta R.K. 1993. Material Selection for Corrosion Control ASM International.

Fontana G. Mars. 1979. Corrosion Engineering. Third edition. Mac Graw Hill Book co, New York.
Jones Denny A. 1992. Prinsiples and Preventation of Corrosion. Macmillan Publishing Company. New York.

Jones D. A. 1972. Analysis of Cathodic Protection Criteria, Corrosion. NACE, Vol 28, No 11.

Morgan J.H. 1987.Catodic Protection. second edition, Nace.

NACE Standard Rp-01-76.1976. Corrosion Control of Steel,Fixed Offshore Platfoms Associated with Petroleum Production. NACE.

Prentice G. 1991. Electrochemical Engineering Principles. Prentice Hall, New Jersey.

Scully J.C. 1975. The Fundamental of Corrosion.second edition, New York.

Shreir L.L., Jarman RA., Burstein G.T. 1994. Corrosion Corrosion Control. Third edition. Newness Butterworths London.

Uhlig H.H., 1985. Corrosion and Corrosion Control. John Willey \& Sons New York. 